\title{
Part Two: Habit and Customs, Obesity and Parkinson's Disease
}

\author{
Muslimat Kehinde Adebisi ${ }^{1,2,3^{*}}$, Li Xuezhong ${ }^{1}$, Ehianeta Teddy and Liuyi ${ }^{1,2}$ \\ ${ }^{1}$ No. 1 People's Hospital Zhenjiang, Jiangsu University, Zhenjiang, China \\ 2Jiangsu University, Zhenjiang, China \\ ${ }^{3}$ Overseas Education College, Jiangsu University, China \\ ${ }^{4}$ Shanghai Institute of Organic Chemistry, Chinese Academy of Sciences, China
}

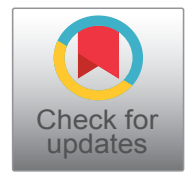

*Corresponding author: Muslimat Kehinde Adebisi, No. 1 People's Hospital Zhenjiang; Overseas Education College, Jiangsu University, Zhenjiang, China

\begin{abstract}
Objective: To establish correlation between lifestyles, obesity and the risks of Parkinson's disease (PD).

To ascertain the effect of PD on Body mass index (BMI).

Methods: Keyword used in searching for similar articles on PubMed were, Obesity, hyperlipidemia, Metabolic syndrome (MetS), Neurodegenerative disorders, Parkinson's diseases (PD). Papers from 2014-2019 related were compiled. Cases at Zhenjiang First people's hospital similar was compiled to draw conclusions. I evaluated the association between years of diagnosis (YOD) of PD and BMI for both male and female patients and compared to controlled groups. There was a statistically significance between YOD of PD and BMI.
\end{abstract}

Conclusion: Meta-analysis showed that YOD is inversely proportional to BMI.

\section{Introduction}

Following Alzheimer's disease, Parkinson's disease (PD) is the second most common age-related neurodegenerative disorder. The motor-related symptoms include bradykinesia, rigidity, tremor and postural instability, while metabolic imbalances, psychiatric and cognitive disorders are typical of the non-motor symptoms [1]. The pathology of PD is yet to be understood but some studies showed that the risk factors were age, obesity, environmental toxins, genetics, physical inactivity [2-4]. Weight loss correlates with the progression of $P D$, in our study we were able to ascertain that lowest BMI was in the most advanced stage.

\section{Parkinson's Disease in China}

The rapid growth in China's economy caused an increase in the risk factors for PD such as obesity [5] and the prevalence was estimated as 18 per 100,000 people in a survey in Shanghai, China. Age adjusted rates give more restricted range of 72-258.8 per 100,000 people. Most of the reports recorded overall crude report ratio of between male and female of all ages 100 and 200 per 100,000 people [6]. PD is common among old people and as the population of China continues to be majorly Old, we can conclude that in the next decade the prevalence of PD in China will grow exponentially.

\section{Risk Factors for PD}

\section{Nutrition}

Some motor symptoms such as dyskinesia increases energy expenditure and some of the medications affects food intake, cognitive impairment can also increase chances of malnutrition, If the diagnosis was made at an older age and the patient has no caregiver, they tend to have higher neurologic and depression score causing for a higher dose of daily levodopa, this predicts malnutrition [7-9], patients like these are at high risk of losing weight and malnourishment has a negative feedback effect on the neurological status.

A systematic review reported a malnutrition prevalence ranges from $0 \%-24 \%$, while $3 \%-60 \%$ of PD patients were found to be at risk [10]. Factors that influences appetite are early satisfaction, constipation, dysphagia

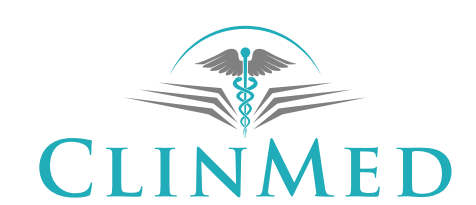

INTERNATIONAL LIBRARY
Citation: Adebisi MK, Xuezhong L, Teddy E, Liuyi (2019) Part Two: Habit and Customs, Obesity and Parkinson's Disease. Int J Neurodegener Dis 2:013. doi.org/10.23937/2643-4539/1710013

Accepted: October 19, 2019; Published: October 21, 2019

Copyright: (C) 2019 Adebisi MK, et al. This is an open-access article distributed under the terms of the Creative Commons Attribution License, which permits unrestricted use, distribution, and reproduction in any medium, provided the original author and source are credited. 
having a significant influence on food intake.

Appetite can be improved by reducing the daily protein intake and also by redistribution while focusing on intake of plant-based protein to improve fiber intake, if the dietary intervention allows reducing total levodopa intake, it should be applied also to nonfluctuating patients. A non-fluctuating patient are those that can reduce levodopa total intakes. Although levodopa Is associated with weight loss, other dopaminergic agents can cause weight gain, and an increase risks of compulsive behavior, such as compulsive eating [11-13].

\section{Genetics}

About $5-10 \%$ of patients suffers from a monogenic form of PD where autosomal dominant mutations in SNCA, LRRK2, and VPS35 and autosomal recessive mutations in PINK1, DJ-1, and Parkin cause the disease with high penetrance [14]. The genetic connection of PD is complex with contribution from certain gene mutations, Mendelian factor such as SNCA, LRRK2, Parkin, Pink1 and non-Mendelian factors (e.g. single nucleotide polymorphisms), Glucocerebrosidase gene mutations (Gaucher disease) are currently the strongest genetic risk factor for PD, the recognition of $\alpha$-synuclein mutations as a uncommon origin of disease and the understanding that this protein is an important factor of all PD in the form of Lewy bodies and Lewy neurites $[15,16]$.

\section{Monogenic loci: Autosomal dominant mutations}

Mutations in the alpha-synuclein gene (SNCA) is uncommon and also point mutations in addition with all locus multiplication, duplication is evidence in family members that is compatible with autosomal dominant inheritance, phenotypes (including myoclonus, severe autonomic dysfunction and dementia in addition to parkinsonism), and looks similar to diffuse Lewy body disease or multiple system atrophy. The patients with SNCA duplications display a classical PD phenotype. Most common known cause of autosomal dominant In PD is the mutation in leucine-rich repeat kinase 2 (LRRK2) This gene has 51 exons, encoding a very large protein, termed Irrk2 (dardarin), this contains two predicted enzyme domain namely (GTPase and kinase) and multiple protein-protein interaction domains showing almost $10 \%$ of the patients with familial PD and a clear autosomal dominant pattern of inheritance. In some studies, approximately up to $70 \%$ of people age 80 years has an incomplete and age-related penetrance estimated for commonest Gly2019Ser mutation. Dopamine neuron loss and a change in glial cell (gliosis) in the substantia nigral is a common feature in patients with LRRK2 mutation, with Lewy body found in these patients [16].

\section{Autosomal recessive forms}

PRKN (parkin, PARK2), PINK1 (PARK6), and DJ-1 (PARK7) no atypical clinical forms presentation, mutations in each cause rare form of parkinsonism with an early onset $(<30$ years) clinical features is presented as pyramidal, dystonic, ocular movement, and cognitive disturbances. Mutations in PINK1 and PARK7 accounts for up to $1-8 \%$, and $1-2 \%$ of the sporadic cases with early-onset. Mutations in parkin accounts for half of the category of the disease onset which is usually before the age of 45 years, and also $15 \%$ of the sporadic cases with onset before 45 [16].

\section{Recently discovered gene mutation}

Vacuolar protein sorting (VPS35 c.1858G > A; p. Asp620Asn) VPS35 is a central component of the tripartite retromer cargo-recognition complex, consisting of VPS35, VPS29 and VPS26a or b, that together form the luminal structure for transport of specific membrane-associated proteins. To date, the role of retromer within neurons is poorly described but the linkage of VPS35p, D620N to Parkinson's disease is likely to be a catalyst for future research. Dynactin DCTN1 mutations provide an elegant opportunity to understand the selective vulnerability of different neuronal population to a neurodegenerative disease, elF4G1 were genetically linked to autosomal dominant late-onset Parkinson's disease with brainstem Lewy body pathology [16].

\section{Metabolic syndrome (Mets)}

The component of Mets are Diabetes mellitus (DM), Central Obesity, Glucose intolerance, Dyslipidemia along with elevated triglycerides, low high density lipoprotein (L-HDL) cholesterol, microalbuminuria, Low density lipoprotein (LDL), cholesterol particles, High blood pressure (HBP), Endothelial dysfunction, high waist circumference, oxidative stress, inflammation, tumors, neurodegeneration, and atherosclerosis-based ischemic cardio- or cerebral-vascular disease. Studies has shown that increased oxidative stress is the core and a general character of metabolism-related disease, making it a risk factor for PD [17]. Fat and Obesity has been reported to have an association with PD, Obesity at middle age increases the chances of neurodegenerative diseases and excessive consumption of glucose had neurotoxicity [18-21]. Hyperhomocysteinemia and Endothelial Dysfunction are risk factors for neurodegenerative diseases $[22,23]$. Stress to the endoplasmic reticulum (ER) and inflammation results in pathogenesis of PD [24-26].

\section{Environmental factors}

There was a connection established between PD and Pesticide this was suspected in 1983, when a chemical found in paraquat (1-methyl-4-phenyl-1,2,3,6-tetrahydropyridine) (MPTP), was said to cause acute Parkinsonism [27]. Studies that reported exposures used it as an estimate for pesticide expo- 
sure effect on PD but it's difficult to pin point because PD occurs late in life $[28,29]$. Some self-reported cases, job exposures to toxins, geographical location was also reported in some patients [30-33].

A study reported association of direct pesticide application defined broadly and specifically, well-water consumption, and farming residences and occupations with PD were evaluated in 319 cases from 308 families and 296 relative and other controls, of the controls, 252 were relative controls from the 308 families with at least one case, and these relative controls included 237 siblings, 10 parents or children, and 5 cousin or avuncular relatives (uncles/aunts/ nephews/nieces). The remaining 44 controls were ascertained as spouse or other unrelated controls or as relative controls in families with no environmental risk factor data available on the case(s). Only 39 of the 319 cases $(12 \%)$ reported having symptoms of PD for two years or less [32,34,35].

\section{Autoimmune disease}

Amyotrophic, lateral sclerosis and multiple sclerosis were associated with risk of $P D$, these diseases were said to have common pathological features such as inflammation, genetic mutation, improper protein aggregates and biochemical defect that leads to cell death [36] Some studies assumed PD to be an autoimmune disease because of the signs of neuroinflammation and peripheral immune infiltration, a Swedish study found that patients with autoimmune diseases and those with higher socio-economic status had a higher risk of Parkinson's disease [37,38]. Reiter's disease was connected to the highest risk for PD and an increased risk was also noted during 1-4 years follow up of ankylosing spondylitis [39].

\section{Body Mass Index (BMI)}

Several reports have had it that patients with $25 \mathrm{BMI}$ $\leq 25 \mathrm{~kg} / \mathrm{m}^{2}<30 \mathrm{~kg} / \mathrm{m}^{2}$ was a risk factor for PD, an association was established between waist circumference and PD amongst non-smokers, increased triceps skinfold thickness, which is an indicator of obesity of the periphery was said to be associated to an increased risk of PD [40-43].

\section{Common view}

Chen, et al. [2] found that $25 \leq \mathrm{BMI}<30$ might have an increased risk of PD compared to $\mathrm{BMI}<25$ in cohort studies but in case-controlled studies $25 \leq \mathrm{BMI}<30$ was not a risk factor for PD compared to Cohort studies.

A report in Mexico pointed out that overweight and obesity is common amongst PD patients, while Underweight and malnutrition were well documented among these patients during the course of the disease. A cross-sectional study including 177 healthy controls and 177 PD patients attending a tertiary care center record- ed a statistically significant difference between BMI between controls and PD patients (29.1 \pm 5.4 versus $27.2 \pm$ $4.7, \mathrm{p}<0.001)$. In the PD Group, two patients were underweight, $32.7 \%$ were within normal range, $46.9 \%$ had overweight, and $19.2 \%$ were obese. Overweight and normal weight were more prevalent in the PD Group ( $p=<0.01$ and $<0.001$, respectively) when compared to controls. He concluded that overweight/obesity are common among patients with PD, while underweight is almost negligible [6].

\section{Conclusion}

PD has been attributed to several metabolic diseases, genetic affiliations, Neurological disease as its risk factors, either of these has just given clue to ascertain a possibility of the disease in the future, might not necessarily be true if close attention is paid to avoid the avoidable risk factors that are glaring, and the non-avoidable, life style modification should be employed to help prevent future PD, Since the main cause is yet to be established we recommend close monitoring of at risk people to reduce the eventuality of PD. Attention should be paid to these metabolic diseases that not only disrupt the system but also affects the medication used decreasing the chances of proper PD management. Neurologist should work hand in hand with endocrinologist and nutritionist to follow up on PD patients for proper management and prognosis.

\section{References}

1. Chaudhuri KR, Healy DG, Schapira AH (2006) Non-motor symptoms of parkinson's disease: Diagnosis and management. Lancet Neurol 5: 235-245.

2. Chen J, Guan Z, Wang L, Song G, Ma B, et al. (2014) Meta-analysis: Overweight, obesity, and parkinson's disease. Int J Endocrinol 2014: 203930.

3. Behari M, Srivastava AK, Das RR, Pandey RM (2001) Risk factors of parkinson's disease in Indian patients. J Neurol Sci 15: 49-55.

4. Abbas MM, Xu Z, Tan LCS (2018) Epidemiology of parkinson's disease-east versus west. Mov Disord Clin Pract 5: 14-28.

5. Morales-Briceno $\mathrm{H}$, Cervantes-Arriaga A, Rodríguez-Violante M, Calleja-Castillo J, Corona T (2012) Overweight is more prevalent in patients with parkinson's disease. Arq Neuropsiquiatr 70: 843-846.

6. Walker RW, Howells AR, Gray WK (2011) The effect of levodopa dose and body weight on dyskinesia in a prevalent population of people with parkinson's disease. Parkinsonism Relat Disord 17: 27-29.

7. Sharma JC, Macnamara L, Hasoon M, Vassallo M, Ross I (2006) Cascade of levodopa dose and weight-related dyskinesia in parkinson's disease (LD-WD-PD cascade). Parkinsonism Related Disorder 12: 499-505.

8. Bachmann CG, Zapf A, Brunner E, Trenkwalder C (2009) Dopaminergic treatment is associated with decreased body weight in patients with parkinson's disease and dyskinesias. Eur J Neurol 16: 895-901.

9. Barichella M, Villa MC, Massarotto A, Cordara SE, Marcze- 
wska A, et al. (2008) Mini nutritional assessment in patients with parkinson's disease: Correlation between worsening of the malnutrition and increasing number of disease years. Nutr Neurosci 11: 128-134.

10. Sheard JM, Ash S, Silburn PA, Kerr GK (2011) Prevalence of malnutrition in parkinson's disease. Nut Rev 69: 520-532.

11. Kumru H, Santamaria J, Valldeoriola F, Marti MJ, Tolosa E (2006) Increase in body weight after pramipexole treatment in parkinson's disease. Mov Disord 21: 1972-1974.

12. Raja M, Bentivoglio AR (2012) Impulsive and compulsive behaviors during dopamine replacement treatment in parkinson's disease and other disorders. Curr Drug Saf 7: 6375.

13. Tuite PJ, Maxwell RE, Ikramuddin S, Kotz CM, Billington CJ, et al. (2005) Weight and body mass index in parkinson's disease patients after deep brain stimulation surgery. Parkinsonism Relat Disord 11: 247-252.

14. Lill CM (2016) Genetics of parkinson's disease. Mol Cell Probes 30: 386-396.

15. Andrew BS, Matthew JF, Vincenzo B (2013) The genetics of parkinson's disease: Progress and therapeutic implications. Mov Disord 28: 14-23.

16. Pei Z, Bo T (2014) Metabolic syndrome: An important risk factor for parkinson's disease. Oxid Med Cell Longev 2014 729194.

17. Abbott RD, Ross GW, White LR, Nelson JS, Masaki KH, et al. (2002) Midlife adiposity and the future risk of parkinson's disease. Neurology 59: 1051-1057.

18. Whitmer RA, Gunderson EP, Barrett-C, Queensberry CP $\mathrm{Jr}$, Yaffe K (2005) Obesity in middle age and future risk of dementia: A 27-year longitudinal population-based study. BMJ 330: 1360

19. Lee EB, Mattson MP (2014) The neuropathology of obesity: Insights from human disease. Acta Neuropathol 127: 3-28.

20. Hu G, Jousilahti P, Bidel S, Antikainen R, Tuomilehto J (2007) Type 2 diabetes and the risk of parkinson's disease. Diabetes Care 30: 842-847.

21. David RT, Natalie JG (2008) Glucose neurotoxicity. Nat Rev Neurosci 9: 36-45.

22. Kruman II, Culmsee C, Chan SL, Kruman Y, Guo Z, et al. (2000) Homocysteine elicits a DNA damage response in neurons that promotes apoptosis and hypersensitivity to excitotoxicity. J Neurosci 20: 6920-6926.

23. Woo KS, Chook P, Lolin YI, Cheung AS, Chan LT, et al. (1997) Hyperhomocysteinemia(e)anemia is a risk factor for arterial endothelial dysfunction in humans. Circulation 96: 2542-2544.

24. Nobutaka H, Yoshikuni M (2017) Twenty years since the discovery of the pakin gene. J Neural Transm 124: 10371054.

25. Yuzuru I, Mariko S, Shigetsugu $\mathrm{H}$, Takumi A, Tsutomu $\mathrm{H}$, et al. (2002) CHIP is associated with Parkin, a gene responsible for familial parkinson's disease, and enhances its ubiquitin ligase activity. Molecular Cell 10: 55-67.

26. Yuzuru I, Mariko S, Ryosuke T (2000) Parkin suppresses unfolded protein stress-induced cell death through its E3 ubiquitin-protein ligase activity. J Biol Chem 275: 3566135664.

27. Langston JW, Ballard P, Tetrud JW, Irwin I (1983) Chronic parkinsonism in humans due to a product of meperidine analog synthesis. Science 219: 979-980.
28. Frigerio R, Sanft KR, Grossardt BR, Peterson BJ, Elbaz A, et al. (2006) Chemical exposures and parkinson's disease: A population-based case control study. Mov Disord 21: 1688-1692.

29. Dana BH, Eden RM, Gregory MM, Jeffrey MS, Rita J, et al. (2008) Pesticide exposure and risk of parkinson's disease: A family-based case control study. BMC Neurol 8: 6.

30. Petrovitch H, Ross GW, Abbott RD, Sanderson WT, Sharp DS, et al. (2002) Plantation work and risk of parkinson disease in a population based longitudinal study. Arch Neurol 59: 1787-1792.

31. Ascherio A, Chen H, Weisskopf MG, O'Reilly E, McCullough ML, et al. (2006) Pesticide exposure and risk for parkinson's disease. Ann Neurol 60: 197-203.

32. Tanner CM, Ross GW, Jewell SA, Hauser RA, Jankovic J, et al. (2009) Occupation and risk of parkinsonism: A multicenter case-control study. Arch Neurol 66: 1106-1113.

33. Kamel F, Tanner C, Umbach D, Hoppin J, Alavanja M, et al. (2007) Pesticide exposure and self-reported parkinson's disease in the agricultural health study. Am J Epidmiol 165: 364-374.

34. Hancock DB, Martin ER, Mayhew GM, Stajich JM, Jewett $R$, et al. (2008) Pesticide exposure and risk of parkinson's disease: A family-based case-control study. BMC Neurol 6-8.

35. Micheal JZ, Robert EB (2017) Pathophysiology of parkinson's disease. Neuropsychopharmacology.

36. Timothy GL, Eric JS, Ahlskog EJ, Henley JR, Shehadeh L, et al. (2008) Beyond parkinson disease: Amyotrophic lateral sclerosis and the axon. PLoS One 1371: e1449.

37. Li X, Sundquist J, Sundquist K (2012) Subsequent risks of parkinson disease in patients with autoimmune and related disorders: A nationwide epidemiological study from Sweden. Neurodegener Dis 10: 277-284.

38. Angela JM, Warren M, Carvey PM (2008) Neuroinflammation and peripheral immune infiltration in parkinson's disease: An autoimmune hypothesis. Cell Transplant 17: 363-372.

39. Leirisalo-Repo M, Sieper J (2006) Reactive arthritis: Epidemiology, clinical features, and treatment. In: Weisman $\mathrm{MH}$, van der Heijde D, Reveille JD, Ankylosing spondylitis and the spondyloarthropathies. Mosby Elsevier, Philadelphia, USA, 53.

40. Wannamethee SG, Shaper AG (2003) Alcohol, body weight, and weight gain in middle-aged men. Am J Clin Nutrition 77: 1312-1317.

41. Elin R, Alessandra G, Fei Y, Rino B, Weimin Y, et al. (2018) Body mass index and risk of parkinson's disease. Neurology 90: e1413-e1417.

42. Pan A, Malik VS, Hao T, Willett WC, Mozaffarian D, et al. (2013) Changes in water and beverage intake and longterm weight changes: Results from three prospective cohorot studies. Int J Obes 37: 1378-1385.

43. Saaksjarvi K, Knekt P, Mannisto S, Lyytinen J, Jaaskelainen T, et al. (2014) Reduced risk of parkinson's disease associated with lower body mass index and heavy leisure-time physical activity. Eur J Epidemiol 29: 285-292.
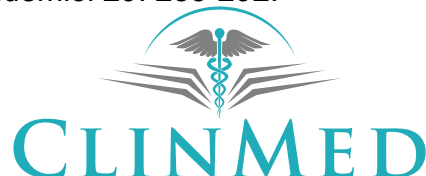

INTERNATIONAL LIBRARY 